\title{
Motion Analysis of Normal Patellar Tendon Reflex
}

\author{
Lai Kuan Tham, Noor Azuan Abu Osman, Wan Abu Bakar Wan Abas, \\ Kheng Seang Lim
}

\begin{abstract}
Background: Reflex assessment, an essential element in the investigation of the motor system, is currently assessed through qualitative description, which lacks of normal values in the healthy population. This study quantified the amplitude and latency of patellar tendon reflex in normal subjects using motion analysis to determine the factors affecting the reflex amplitude. Methods: 100 healthy volunteers were recruited for patellar tendon reflex assessments which were recorded using a motion analysis system. Different levels of input strength were exerted during the experiments. Results: A linear relationship was found between reflex input and reflex amplitude $(r=0.50, P<0.001)$. The left knee was found to exhibit $26.3 \%$ higher reflex amplitude than the right $(P<0.001)$. The Jendrassik manoeuvre significantly increased reflex amplitude by $34.3 \%(P=0.001)$; the effect was especially prominent in subjects with weak reflex response. Reflex latency normality data were established, which showed a gradual reduction with increasing input strength. Conclusion: The quantitative normality data and findings showed that the present method has great potential to objectively quantify deep tendon reflexes.
\end{abstract}

RÉSUMÉ: Analyse du mouvement du réflexe rotulien normal. Contexte : L'évaluation des réflexes, un élément essentiel de l'examen du système moteur, est effectué actuellement par une description qualitative des réflexes pour laquelle il n'existe pas de valeurs normales dans la population en bonne santé. Cette étude a quantifié l'amplitude et la latence du réflexe rotulien chez des sujets normaux au moyen d'une analyse du mouvement pour déterminer les facteurs qui influencent l'amplitude du réflexe. Méthode : 100 volontaires sains ont été recrutés afin de procéder à des évaluations du réflexe rotulien qui a été enregistré par un système d'analyse du mouvement. Différents niveaux de force de stimulation ont été exercés pendant les expériences. Résultats : Nous avons constaté qu'il existe une relation linéaire entre le stimulus et l'amplitude du réflexe $(\mathrm{r}=0,50 ; \mathrm{p}<0,001)$. L'amplitude du réflexe du genou gauche était de $26,3 \%$ supérieure à celle du genou droit $(\mathrm{p}<0,001)$. La manœuvre de Jandrassik augmentait significativement l'amplitude, soit de 34,3\% ( $\mathrm{p}=0,001)$. Cet effet était particulièrement évident chez les sujets dont la réponse était faible. Nous avons recueilli des données sur le temps de latence normal qui diminuait graduellement à mesure que la force du stimulus augmentait. Conclusion : Ces données quantitatives sur le réflexe normal et ces constatations démontrent que la méthode que nous avons utilisée présente un excellent potentiel pour quantifier objectivement les réflexes ostéo-tendineux.

Can J Neurol Sci. 2013; 40: 836-841

Deep tendon reflex is the involuntary reaction of muscle spindles as a stretch is applied to the tendon ${ }^{1}$. The tendon stretch leads to a sudden contraction of related muscles in response to the stimuli ${ }^{2,3}$. Reflex assessment is important in the investigation of abnormal motor systems ${ }^{4}$. The response is affected by many factors such as gender, age, subject's position, and mental condition, which plays multiple roles in contributing to the variation of reflex responses ${ }^{4-6}$. However, the subject's position, mental and muscle condition leading to reflex variability are unavoidable $\mathrm{e}^{7,8}$. In addition, the elderly have been found to have reduced reflex responses ${ }^{9,10}$. A previous study on the effect of gender found higher reflex response in males compared to females ${ }^{10}$. Height, which indicates the length of nerve conduction pathway, is also found to influence reflex, and a linear relationship between height and reflex response has been reported $^{11-13}$.

Extensive research has been conducted over the years to quantify reflex response. Most of the existing studies that quantify deep tendon reflexes involved the use of manually operated hammer attached to a sensor. The study of Stam and van Crevel used a reflex hammer attached to a piezo-electric transducer to collect input data ${ }^{13}$. Husemann and Behse measured the patellar tendon reflexes using a reflex hammer connected to a piezo-element ${ }^{14}$. Ogawa et al produced latency value of the Achilles tendon reflex from groups of workers exposed to lead; the study used a manual reflex hammer generating short circuit as the triggering pulse during the tendon $\operatorname{tap}^{12}$.

Surface electromyography was used to measure reflex responses in many studies including those mentioned above $\mathrm{e}^{12-14}$. Other studies required attachments of sensors on the body parts which restrained movements of the subject ${ }^{15,16}$. Such fixations

From the 1 Department of Biomedical Engineering (LKT, NAAO, WABWA), Faculty of Engineering; Division of Neurology (KSL), Faculty of Medicine, University of Malaya, Kuala Lumpur, Malaysia.

Received October 9, 2012. Final Revisions Submitted May 6, 2013. Correspondence to: Lai Kuan Tham, Department of Biomedical Engineering, Faculty of Engineering, University of Malaya, 50603 Kuala Lumpur, Malaysia.

Email: laikuan_tam@hotmail.com. 
on subjects might lead to discomfort and affect the natural response of a reflex ${ }^{17}$. Therefore, a reflex quantification method that allows subject to remain comfortable and relax throughout the test is required for more accurate measurements. Motion analysis that avoids major fixations on the subject was proposed for this study. The method, which required only the attachment of reflective markers, allowed subjects to sit with their desired position. Thus, the possibility to develop anxiousness during the experiments could be minimized.

The Jendrassik manoeuvre (JM) is a well-known technique of reinforcement applied during the encounter of unresponsive tendon reflexes ${ }^{5}$. This method of reinforcement is performed by mental distraction such as teeth clenching or pulling apart the hooked fingers ${ }^{18}$. Though JM was practised widely in clinical neurology and its efficacy was statistically proven ${ }^{10,11}$, the magnitude of its impact on tendon reflex was not previously measured.

The assessment of tendon reflex latencies is very useful in the diagnosis of neurological disorders especially peripheral neuropathies and radiculopathies ${ }^{11}$. The conduction time or velocity along the peripheral nerve, particularly the proximal segment, is evaluated by obtaining measurements of tendon reflex latency ${ }^{11,12,19}$.

The aim of this study was to quantify the amplitude and latency, and to establish the normality of patellar tendon reflex in normal subjects using motion analysis. In addition, we also aimed to determine the factors affecting the reflex amplitude, and to measure the magnitude of the impact of JM.

\section{METHODS}

One hundred volunteers, 50 males and 50 females, aged 21 to 32 years were recruited in this study. All volunteers were healthy

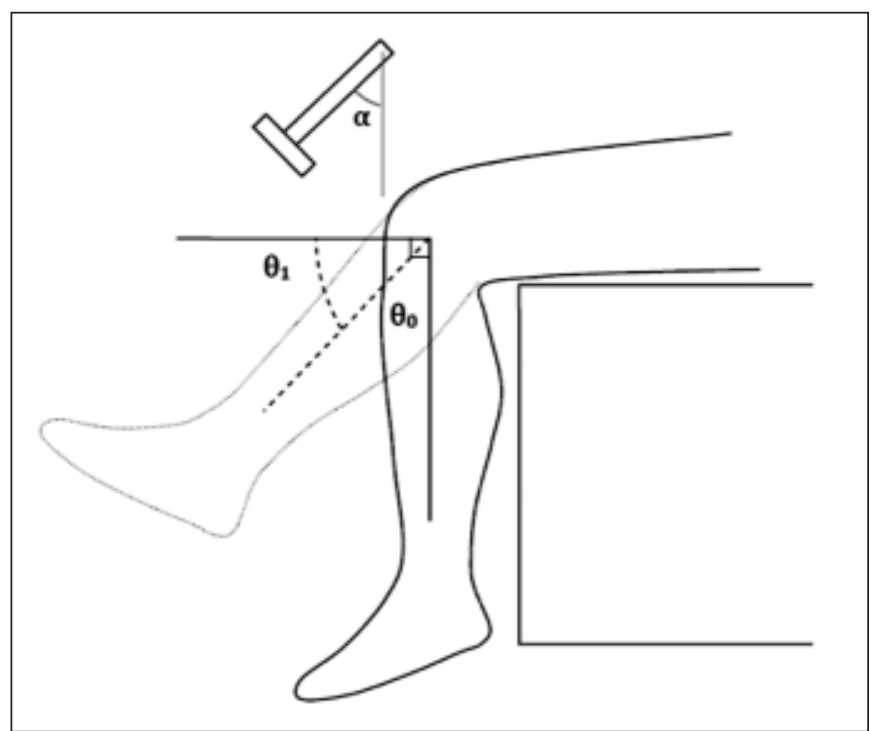

Figure 1: Measurement of tapping angle and reflex amplitude. The tapping angle was measured from the longitudinal line parallel to the $y$ axis of the knee joint. The reflex amplitude was measured as the difference of knee angle $\left(\theta_{0}-\theta 1\right)$ between the static position $(\theta 0$, approximately $\left.90^{\circ}\right)$ and the maximum knee extension $\left(\theta_{1}\right.$, indicated as dotted line). with no past and present history of neurological disorder or diabetes mellitus. This study has been approved by a board in the Department of Biomedical Engineering of the University of Malaya. Written consent was obtained from the participants.

An ordinary Queen Square reflex hammer was used to elicit reflexes in all experiments. Patellar tendon reflex examination was performed by trained physician under the recording of motion analysis system Vicon Nexus 1.6 (Oxford Metrics, Oxford, UK). Sixteen reflective markers were attached on the lower limb of the subject according to the Plug-in-Gait Marker Placement ${ }^{20}$. During the test, each subject was requested to sit upright with both legs not touching the ground; movements of the body were not restricted. If symptoms of anxiety such as muscle tension were noticed in the subject, the experiment would be stopped and reinitiated after a minimum of five minutes' rest.

The assessment of patellar tendon reflex began with the left leg, followed by the right. For each experiment, the patellar tendon was tapped with tapping angle of $15^{\circ}, 30^{\circ}, 45^{\circ}, 60^{\circ}, 75^{\circ}$, and $90^{\circ}$, measured from the longitudinal line parallel to the long axis of the leg, as shown in Figure 1. Velocities were calculated from the coordinates of reflex hammer collected in the experiments. The maximum velocity of the reflex hammer was defined as the tapping velocity in a single trial. Five taps were applied to the tendon at every tapping angle with an interval of 10 to 15 seconds between each tap. Jendrassik manoeuvre was performed in each subject, in which the subject was asked to interlock and pull the fingers apart, and five taps at tapping angle of $45^{\circ}$ were applied with an interval of 10 to 15 seconds between the taps. For every step, the best reflex response among all five taps was documented.

The reflective marker, which was attached at the lateral epicondyle of the knee joint bilaterally, served as the reference point during reflex examination. The difference of knee angle between the static position and the maximum knee extension was regarded as reflex amplitude, as shown in Figure 1. Reflex latency was measured as the interval between tendon tap and the onset of knee extension.

Table 1: Mean and one standard deviation of reflex amplitude in relation to tapping angle

\begin{tabular}{ccc}
\hline Tapping angle $\left(^{\circ}\right)$ & $\begin{array}{c}\text { Mean reflex } \\
\text { amplitude }\left(^{\circ}\right)\end{array}$ & Standard deviation \\
\hline 15 & 0.18 & 0.20 \\
30 & 1.97 & 3.38 \\
45 & 5.25 & 6.05 \\
60 & 8.25 & 6.63 \\
75 & 8.63 & 7.54 \\
90 & 9.53 & 7.30 \\
\hline
\end{tabular}




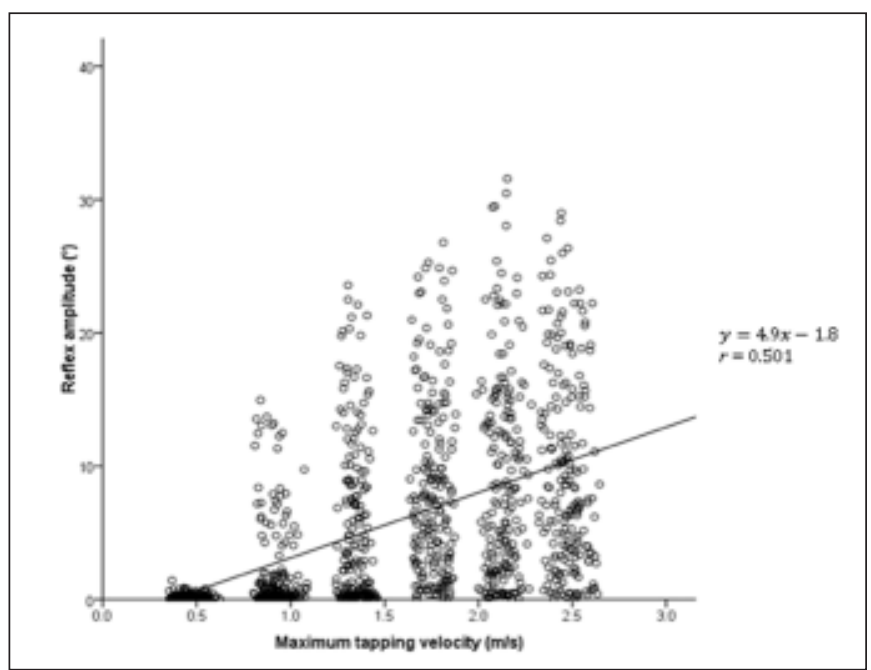

Figure 2: Representative relationship between the maximum tapping velocity and reflex amplitude.

Data according to input strength were analyzed using the Pearson's correlation coefficient and simple linear regression. Comparisons of reflex amplitude between genders were done using the independent student t-test. The effects of body side and $\mathrm{JM}$ on reflex responses were analyzed using the paired t-test. Lastly, the paired-t test was also used to compare the reflex latency at different input strength. Statistical significance of $P<0.05$ was used for all tests unless otherwise stated.

\section{RESULTS}

The mean age of the subjects was $24.8 \pm 2.2$ years $(21-32$ years).

\section{Relationship between tapping strength and reflex amplitude}

Patellar tendon reflex amplitudes in relation to different tapping angles are shown in Table 1. Reflex amplitude was found to increase gradually with the increase of tapping angle, an indirect indicator of stimulus strength.
Reflex amplitude was strongly correlated with maximum tapping velocity (Pearson's correlation coefficient was $0.501, P$ value $<0.001)$. Figure 2 indicates a linear relationship between the two parameters, with a linear equation.

\section{Reflex amplitude between genders}

The reflex amplitude of male subjects was significantly higher than female subjects at tapping angle of $15^{\circ}(P=0.035)$ and $90^{\circ}(P=0.037)$, as shown in Table 2. Female subjects, on the other hand, were showing greater reflex amplitude at tapping angle of $30^{\circ}$ and $45^{\circ}$, but the differences were not statistically significant.

\section{Left-right asymmetry in the patellar tendon reflex}

Left-right asymmetry was found in the patellar tendon reflex in the study, in which the left knee had $26.3 \%$ greater reflex amplitude compared to the right knee $\left(6.29 \pm 7.14^{\circ}\right.$ versus 4.98 $\left.\pm 6.33^{\circ}, P<0.001, \mathrm{n}=1200\right)$. The actual left-right difference in mean reflex amplitude was $1.31^{\circ}$.

\section{Effect of Jendrassik manoeuvre on reflex amplitude}

Patellar tendon reflex amplitude was found to significantly increase by $34.3 \%$ with $\mathrm{JM}$ as compared to the baseline reflex amplitude elicited at tapping angle of $45^{\circ}$ without the manoeuvre $\left(7.05 \pm 6.51^{\circ}\right.$ versus $\left.5.25 \pm 6.05^{\circ}, P=0.001, \mathrm{n}=400\right)$. The changes in reflex amplitude with JM in all subjects were calculated, and plotted in relation to the baseline reflex amplitude (tapping angle of $45^{\circ}$ without JM), as shown in Figure 3 . The subjects were categorized into two subgroups; a group with baseline reflex amplitude below the mean reflex amplitude (small AMP) and a group with baseline reflex amplitude above the mean (large AMP). A greater increase in reflex amplitude with JM was found in the subgroup with small AMP, as shown in Figure 3. For this subgroup, the increase of reflex amplitude with JM was $79.51 \%$. For subgroup with large AMP, $60.26 \%$ exhibited a decrease in reflex amplitude with JM.

\section{Reflex latency}

As shown in Table 3, the latency of patellar tendon reflex decreased gradually as the tapping angle increased. Reflex

Table 2: Comparison of reflex amplitudes $\left({ }^{\circ}\right.$, mean \pm SD) between genders

\begin{tabular}{cccc}
\hline Tapping angle $\left({ }^{\circ}\right)$ & Male knee $(\mathrm{n}=100)$ & Female knee $(\mathrm{n}=100)$ & $P$ value \\
\hline 15 & $0.21 \pm 0.24$ & $0.15 \pm 0.16$ & $0.035^{*}$ \\
30 & $1.60 \pm 2.81$ & $2.35 \pm 3.84$ & 0.116 \\
45 & $4.20 \pm 5.68$ & $6.29 \pm 6.25$ & 0.116 \\
60 & $8.41 \pm 6.74$ & $8.09 \pm 6.54$ & 0.731 \\
75 & $8.29 \pm 6.91$ & $8.98 \pm 8.14$ & 0.519 \\
90 & $10.6 \pm 7.32$ & $8.46 \pm 7.15$ & $0.037^{*}$ \\
\hline
\end{tabular}

* Statistical significance difference $(\mathrm{P}<0.05)$ 


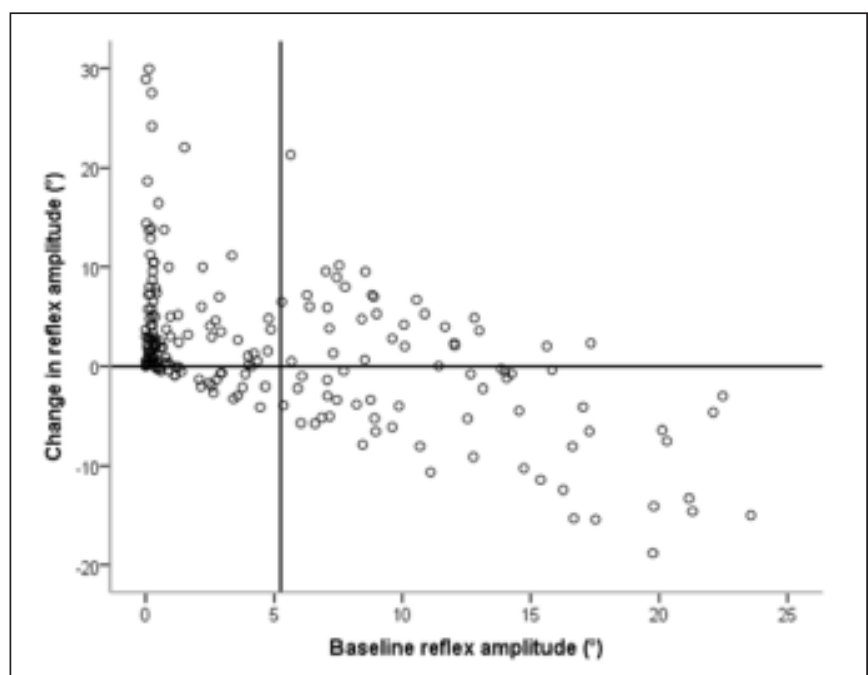

Figure 3: The change in reflex amplitude with JM in relation to the baseline reflex amplitude elicited with tapping angle of $45^{\circ}$ without the manoeuvre $(n=200)$. Horizontal line indicates no change in reflex amplitude with JM, and vertical line indicates the mean baseline reflex amplitude. An increase in reflex amplitude with JM (as indicated by dots above the horizontal line) was mostly found in the subgroup with small AMP (as indicated by the dots left to the vertical line).

latency for tapping angle of $30^{\circ}$ was significantly longer compared to $60^{\circ}(P=0.011)$ and $90^{\circ}(P=0.019)$. Reflex latency with tapping angle of $60^{\circ}$ was also significantly longer than $90^{\circ}$ $(\mathrm{P}=0.003)$. There was no significant left-right difference in patellar tendon reflex latency.

\section{Discussion}

\section{Relationship between tapping strength and reflex amplitude}

Normal values of patellar tendon reflex amplitudes in young adults were established in this study. The quantified values still show large variation and these mirror the results of some previous studies ${ }^{6,13}$. In this study, the tapping angle is correlated to the force applied to the tendon based on two physics theory, i.e.; (1) the theory of conservation of mechanical energy, as $v=\sqrt{2 g L(1-\cos \theta)}$ where $v$ is the tapping velocity, $g$ is the gravitational acceleration, $L$ is the handle length of reflex hammer, and $\theta$ is the tapping angle; (2) Newton's second law. The results showed significant effect of tapping force on reflex amplitude. Thus, tapping strength must be taken into consideration in clinical deep tendon reflex interpretation. On the other hand, the mean reflex amplitude of $5.25^{\circ}$ produced by the tapping angle of $45^{\circ}$, an angle commonly used in daily clinical practice ${ }^{21}$, might be difficult to observe. Reflex quantification methods will enable clinicians to grade reflexes more accurately.

The linear relationship between reflex input (maximum tapping velocity) and output (reflex amplitude) was in agreement with earlier studies ${ }^{22,23}$. Other studies found the relation between stimulus and response to be logarithmic $6,13,24,25$. These differences between other studies are due to variations in the input parameters, e.g. peak tapping force ${ }^{24-26}$ and deceleration of hammer ${ }^{6,13}$; and the output parameters, e.g. peak angular speed $^{24}$, peak reflex torque ${ }^{26}$, and electromyography amplitude ${ }^{6,13}$.

\section{Comparison of reflex amplitude between genders}

Female subjects of the study showed greater reflex amplitudes than males at smaller tapping angles, indicated that female has higher sensitivity to lower reflex input. Conversely, male subjects exhibited higher reflex amplitude than female at larger tapping angles, probably because male has greater muscle mass to produce greater output when the reflex input is optimised. The relationship between muscle mass and reflex output, however, requires further exploration. In a clinical study by Lim et al, healthy adult males have been shown to be more likely to have hyperreflexia when compared to females, which is comparable with our results obtained with larger reflex input ${ }^{10}$.

\section{Reflex asymmetry}

Left-right asymmetry of reflexes noted in this study has been previously reported in healthy subjects, both in experimental ${ }^{13}$ and clinical studies ${ }^{10}$. Nevertheless, the difference noted in the clinical study was not statistically significant, possibly because the lack of sensitivity in bedside reflex assessment. In this study,

Table 3: Summary of patellar reflex latencies $(s$, mean \pm SD) in general and the left and right

\begin{tabular}{lllllll}
\hline Tapping angle $\left(^{\circ}\right)$ & \multicolumn{2}{l}{ Left } & Right & \multicolumn{2}{l}{ Overall } \\
\cline { 2 - 7 } & Mean \pm SD & $\mathrm{n}$ & Mean \pm SD & $\mathrm{n}$ & Mean \pm SD & $\mathrm{n}$ \\
\hline 30 & $0.12 \pm 0.04$ & 32 & $0.16 \pm 0.18$ & 31 & $0.13 \pm 0.10^{\mathrm{a}, \mathrm{b}}$ & 63 \\
45 & $0.15 \pm 0.17$ & 69 & $0.11 \pm 0.05$ & 53 & $0.12 \pm 0.11$ & 122 \\
60 & $0.12 \pm 0.08$ & 97 & $0.11 \pm 0.04$ & 84 & $0.12 \pm 0.06^{\mathrm{b}}$ & 181 \\
75 & $0.10 \pm 0.05$ & 83 & $0.11 \pm 0.04$ & 82 & $0.11 \pm 0.04$ & 165 \\
90 & $0.09 \pm 0.04$ & 94 & $0.10 \pm 0.04$ & 86 & $0.10 \pm 0.04$ & 180 \\
\hline
\end{tabular}

${ }^{\text {ap }}<0.05$ as compared to tapping angle of $60^{\circ}$; ${ }^{\text {b }}<0.05$ as compared to tapping angle of $90^{\circ}$. 
the left-right difference was statistically significant with $26.3 \%$ greater reflex amplitude in the left knee, though the actual difference was just $1.31^{\circ}$. The left-right asymmetry is postulated to relate to the cortical dominance. Conversely, comparison between participants with left and right handedness was not performed, as limited by small sample size of left-handed participants. The asymmetry could also be due to the fixed sequence of testing, in which left side was tested first in all subjects. Randomisation of the site of testing in future study will resolve this possibility.

\section{The effect of Jendrassik manoeuvre}

The effect of JM was statistically proven in the study, with an increase of reflex amplitude by $34.3 \%$, comparable to previous studies $^{10,11}$. Nevertheless, what was not previously known is that the effect of JM can be suppressing in those with strong baseline reflex response, in addition to reinforcing in individual who exhibit weaker reflex output. Previous study on JM indicated a supraspinal influence on tendon reflex, postulated to be due to reduction of tonic presynaptic inhibition ${ }^{27}$. This study, however, suggests that JM has a modulation effect on tendon reflex, both enhancing and inhibiting depending on the baseline reflex response. Further neurophysiological study is required to investigate the underlying mechanisms leading to the above mentioned findings.

\section{Reflex latency}

The normal values of patellar tendon reflex latency are established in this study according to tapping angle and side of body. However, the values of reflex latency found in the study are significantly higher compared to the latencies of other studies using electromyography ${ }^{11,13,14,19}$. This is due to the increased time taken for initial myofibrillar contraction to translate into shortening of the muscle's length and hence extension of the knee. In addition, reflex latency is not a static value, regardless of tapping strength. Latency comparison between individuals with peripheral neuropathy and the control using a fixed reflex input is needed to support its usefulness in clinical practice.

\section{Study limitation}

The present study was performed in the laboratory with static cameras setup while reflective markers were attached to the subject and reflex hammer. The application of stationary motion capture system in clinical reflex assessment is in fact demanding and laborious. Thus, future work includes modifications of the approach in order to receive wide acceptance.

Normality data that is limited by the small age range was also a limitation of this study. Reflex measurements will be further collected from different age groups that might serve as the baseline reference for all ages. In addition, quantification of other deep tendon reflexes is necessary to establish a complete normality database, providing an objective alternative for reflex assessment.

\section{CONCLuSIONS}

The proposed technique produced quantitative normal values of patellar tendon reflex amplitude according to different tapping parameters, which has a great potential to be established as a bedside tool in quantifying deep tendon reflexes. The variation of patellar tendon reflex in healthy subjects remained high as found in earlier studies.

\section{ACKNOWLEDGEMENTS}

This study was supported by the Malaysia UM/MOHE/HIR grant (Project number: D000010-16001).We would like to thank all the volunteers, and Lim Lor Shee, Chung Yik Han, and Mohd Firdaus Mohd Jamil for their excellent assistance, and Nemala Nalathamby for her assistance in editing this manuscript.

\section{REFERENCES}

1. Porter NC, Weiner WJ. The neurologic examination. In: Weiner WJ, Goetz CG, editors. Neurology for the non-neurologist. 5th ed. Philadelphia: Lippincott Williams \& Wilkins; 2004. p. 1-20.

2. Campbell WW. DeJong's the neurologic examination. 6th ed. Philadelphia: Lippincott Williams \& Wilkins; 2005.

3. Walker HK. Deep tendon reflexes. In: Walker HK, Hall WD, Hurst JW, editors. Clinical methods: The history, physical and laboratory examinations. 3rd ed. London: Butterworth Publishers; 1990.

4. Toft E, Sinkjaer T, Espersen GT. Quantitation of the stretch reflex. Technical aspects and clinical applications. Acta Neurol Scand. 1989;79:384-90.

5. Dick JPR. The deep tendon and the abdominal reflexes. J Neurol Neurosurg Psychiatry. 2003;74(2):150-3.

6. Stam J, Tan KM. Tendon reflex variability and method of stimulation. Electromyogr Clin Neurophysiol. 1987;67(5): 463-7.

7. Hunt CC. Temporal fluctuation in excitability of spinal motoneurones and its influence on monosynaptic reflex responses. J Gen Physiol. 1955;38(6):801-11.

8. Rudomin P, Dutton H. Effects of conditioning afferent volleys on variability of monosynaptic responses of motorneurones. J Neurophysiol. 1969;32(2):140-57.

9. Carel RS, Korczyn AD, Hochberg Y. Age and sex dependency of the Achilles tendon reflex. The American Journal of the Medical Sciences. 1979;278(1):57-63.

10. Lim KS, Bong YZ, Chaw YL, et al. Wide range of normality in deep tendon reflexes in the normal population. Neurol Asia. 2009;14: 21-5.

11. Frijns CJ, Laman DM, van Duijn MA, van Duijn H. Normal values of patellar and ankle tendon reflex latencies. Clin Neurol Neurosurg. 1997;99(1):31-6.

12. Ogawa Y, Hirata M, Okayama A, Ichikawa YE, Goto S. Latency of the Achilles tendon reflex for detection of reduced functions of the peripheral nervous system in workers exposed to lead. Br J Ind Med. 1993;50:229-33.

13. Stam J, van Crevel H. Measurement of tendon reflexes by surface electromyography in normal subjects. J Neurol. 1989;236(4):231-7.

14. Husemann U, Behse F. Reflex time of the knee jerk in controls, spasticity, radiculopathy and neuropathy. EEG-EMG. 1993;24 (4):280-5

15. Huang $\mathrm{H}$, Zhang L, Rymer WZ. A computer-controlled electromechanical hammer to quantify tendon reflex. 19th Annual International Conference of the IEEE Engineering in Medicine and Biology Society; 1997; Chicago, United States of America; 1997.

16. Simons DG, Lamonte RJ. Automated system for the measurement of reflex responses to patellar tendon tap in man. Am J Phys Med. 1971;50(2):72-9. 
17. LeMoyne R, Dabiri F, Jafari R. Quantified deep tendon reflex device, second generation. J Mech Med Biol. 2008;8:75-85.

18. Jendrassik E. Beiträge zur Lehre von der Sehnen-Reflexen Dtsch Arch Klin Med. 1883;33:177-99.

19. Péréon Y, Nguyen The Tich S, Fournier E, Genet R, Guihéneuc P. Electrophysiological recording of deep tendon reflexes: Normative data in children and in adults. Neurophysiol Clin. 2004;34:131-9.

20. Kadaba MP, Ramakrishnan HK, Wootten ME. Measurement of lower extremity kinematics during level walking. J Orthop Res. 1990;8(3):383-92.

21. Tham LK, Abu Osman NA, Lim KS, Pingguan-Murphy B, Wan Abas WAB, Mohd Zain N. Investigation to predict patellar tendon reflex using motion analysis technique. Med Eng Phys. 2011;33(4):407-10.

22. Gottlieb GL, Agarwal GC. Response to sudden torques about ankle in man: myotatic reflex. J Neurophysiol. 1979;42:91-106.
23. Wadman WJ, Boerhout W, Denier van der Gon JJ. Responses of the arm movement control system to force impulses. J Hum Mov Stud. 1980;6:280-302.

24. Mamizuka N, Sakane M, Kaneoka K, Hori N, Ochiai N. Kinematic quantitation of the patellar tendon reflex using a tri-axial accelerometer. J Biomech. 2007;40:2107-11.

25. Marshall GL, Little JW. Deep tendon reflexes: A study of quantitative methods. J Spinal Cord Med. 2002;25:94-9.

26. Zhang L-Q, Huang H, Silwa JA, Rymer WZ. System identification of tendon reflex dynamics. IEEE Trans Rehabil Eng. 1999;7(2): 193-203.

27. Zehr EP, Stein RB. Interaction of the Jendrássik maneuver with segmental presynaptic inhibition. Exp Brain Res. 1999;124(4): 474-80. 